\title{
Raw-earth housing in Antioquia, Colombia
}

\author{
B. E. Saldarriaga Molina \\ School of Architecture, Universidad Pontificia Bolivariana, Colombia
}

\begin{abstract}
Taking into account the issues with public housing developments in Colombia and consequently in Antioquia, solutions are intended for applications that open future possibilities for the national context. The Universidad Pontifica Bolivariana (UPB) and the Government of Antioquia promote a research project to develop low cost housing based on two components: rammed earth and reinforced concrete. This paper deals with the raw earth module of that investigation. After evaluating the guidelines for social housing in Antioquia and previous developments carried out, a number of proposals were formulated to solve the accumulated deficit of Antioquia. The suggested solutions take into account the legacy of earth-based construction in Colombia and also analyse international, Latin-American, Colombian precedents in raw earth construction. At the same time the different regions of Antioquia were visited, with the intent to incorporate the local housing models and techniques, their constructive culture, their natural and local resources, and environment. Workshops were held alongside these visits and communities from across the different regions of Antioquia were invited to learn from the different construction methods promoted by the research project. Two construction methods, metal structure bahareque (wattle and daub) and compressed earth blocks (CEB), were used to build housing prototypes as part of the research project. These prototypes serve as a proposal for future housing developments in Antioquia.

Keywords: housing, raw earth, rammed earth, bahareque, compressed earth bricks, flexibility.
\end{abstract}

\section{Introduction}

This paper is based on a research project sponsored and financed jointly by the Universidad Pontificia Bolivariana (UPB) School of Architecture and the Office of the Governor of Antioquia through its Empresa de Vivienda de Antioquia- 
VIVA, public institution in charge of the Department of Antioquia's housing program. The research project is currently headed by the Architecture and Urbanism Lab (LAUR) and Technical Experimentation and Studies Lab (LEET) research groups of the UPB School of Architecture.

The main objective of the investigation is to generate technical and architectural construction plans for low-cost housing in Antioquia, with a strong emphasis on raw earth as an alternative construction material with a low environmental impact.

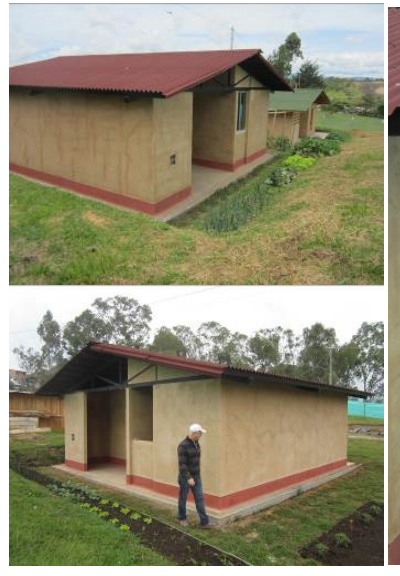

Figure 1: Metal structure bahareque prototype.

The use of raw earth provides an opportunity to develop housing at low production costs and with a high flexibility in its use, allowing proposed techniques to provide a solution to current housing demand in the Department of Antioquia, while at the same time promoting construction elements that are more easily adjusted to the bioclimatic needs and the building traditions of the different regions. Sustainable building practices are encouraged through the use of local resources, especially the soil.

As part of the research process, the use of raw earth as a construction material was analysed both locally and abroad, taking into account historic and contemporary examples. International examples of raw earth constructions, different techniques, legal regulation and practices from different countries in Asia, Africa Europe and America were taken into account in the formulation and design of the construction methods developed by the research project. Different examples in Antioquia were also taken into account, among them the Casa Viva neighbourhood in Vegachi and the Guillermo Gaviria Correa housing development in Sonson as experiences where raw earth construction was used, but where its potential could be enhanced.

As said of Hassan Fathy by Rotondaro [1] in his article in the 2012 critical seminar held in Argentina the influence of innovation technology on constructive and projectual traditions: the case of earth architecture in NOA: 
"The local man builds his house using mud, or mud bricks, which he obtains from the ground and dries under the sun. And here, in any place in Egypt, is the answer to our problem. Here, for years, for centuries, man has used, with great care and wisdom, the more obvious construction materials, while we, with the modern ideas we learned in school would never even dream of using a material as absurd as mud for something as serious as building a house." "One man alone cannot build a house on his own, but ten men can easily build ten houses."

It is important to note that raw earth has had widespread use as a building material throughout Colombia's history, not only through its pre-Columbian use by indigenous groups as seen with the Tayrona building practices in the Sierra Nevada of Santa Marta, but also in the development of Colonial architecture in places like Barichara, Department of Santander; Mompox and Cartagena, Department of Bolivar and Santa Fe de Antioquia, in the Department of Antioquia. Different techniques used in Colombia include the bahareque (wattle and daub), tapia (mud wall) and CEBs, each with its own constructive tradition.

An important precedent in the Colombian context is the CINVA RAM, a machine developed by the National University of Colombia in 1952 capable of producing CEBs on an industrial scale. This machine allows for an easy production of blocks using a long lever to compress a cement-soil mixture. This machine is capable of producing CEBs en masse, making the process much more efficient and allowing for larger scale applications of raw earth construction. The CINVA RAM is an international standard for compressed earth block making.

Nevertheless, over the last 50 years many of these techniques have lost strength, having been replaced by new methods and materials. This change has in turn altered construction practices that in many cases ignore the surroundings and change the way buildings and people relate to their environment.

Having analysed the different national and international practices for raw earth construction two methods were formulated within the research project. Each of these methods takes elements from previous examples of raw earth construction in Colombia, however both methods were explored for the possibility of being developed on a larger scale.

In an attempt to preserve the cultural heritage of earth-based construction techniques in Colombia and to promote sustainable construction practices two different construction techniques were proposed as relevant alternatives to provide solutions to the current housing deficit in Antioquia. This was done under the premise of promoting designs and practices that are conscious about their local environment, and flexible enough to adapt to its corresponding requirements. They are also built with the possibility for progressive growth, both horizontally and by increasing the number of floors in each house.

Two techniques were adopted in the research process: bahareque (wattle and daub) and CEBs. Both construction systems were designed to meet the technical structural requirements of Colombian construction regulations: specifically the NTC-5324 [2] (from 2004) and NSR-2010 [3] (Technical Construction Norm and Seismic Resistance Norm by their initials in Spanish). Characterization of the soil is critical for the proper realization of earth-based construction techniques. The aim was to use local resources whenever it was possible to satisfy the requirements 
of Colombian regulation. This requires extensive analysis of the soil available to identify its properties to determine its possible use and the extent to which they need to be stabilized to meet the legal requirements.

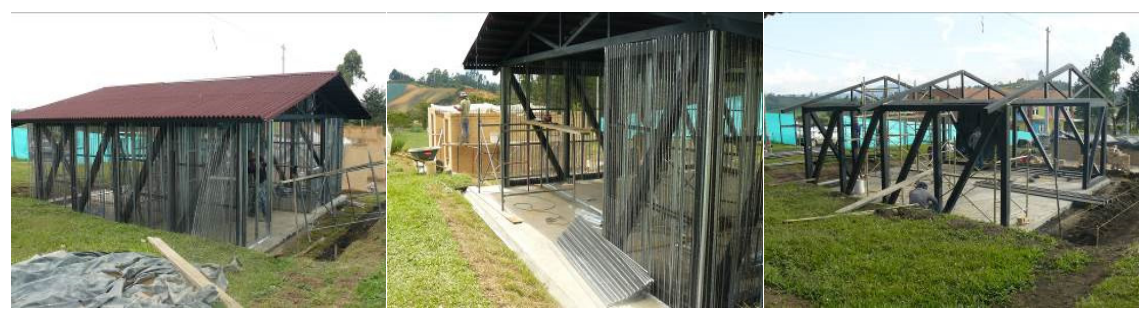

Figure 2: Metal structure bahareque construction process.

The construction materials and designs were also adapted from their traditional counterparts to be able to meet with the capacity and efficiency requirements for the development of low-cost housing. Another consideration in the development of these construction techniques was the ability to develop construction materials that were flexible enough to adjust to the bioclimatic needs and those of their users.

In order to identify both the bioclimatic needs and the traditional construction techniques a series of visits were organized to the different regions of Antioquia. Consequently, one out of each of the 9 regions in which the 125 municipalities of Antioquia are grouped was visited. Intensive workshops were held alongside each visit, where communities from all over the region were invited to learn from the different construction methods promoted by the research project. Methods, practices and general knowledge about raw earth as an efficient, low cost, sustainable material was socialised with the communities during these workshops. As Saldarriaga Roa [4] mentions in an article published in Premio Corona: Guía hábitat rural y vivienda Campesina en Colombia:

"In traditional housing it is possible to note the variety of contributions and traditions of each of the different phases of the settlement of the Colombian territory, from the pre-Columbian stages up to the present. The persistence of ancient traditions in regional construction habits is explained, in part, by their complementarity with the local climate and the local agricultural economy, but also with the advantages that these traditions offer to the rural population in terms of the repertoire of spatial units that account for their different housing and workspace needs, as well as the availability of nearby resources for construction."

Observation of the different building typologies and construction elements used in the regions was also carried out during these visits. Many of these elements were adopted into the design proposals developed during the investigation in order to incorporate the local knowledge and "know-how" of the different communities into the construction processes.

A technical analysis of the weather, precipitation, temperature and other bioclimatic conditions was elaborated during the different visits in order to adjust the housing designs to the requirements of each of the regions. 
The different municipalities visited in each region of Antioquia were:

Yarumal (Northern Antioquia Region)

Apartado (Uraba Region)

Caucasia (Lower Cauca Region)

Hispania (South-western Antioquia Region)

Marinilla (Eastern Antioquia Region)

Puerto Nare (Middle Magdalena Region)

Santa Fe (Western Antioquia Region)

Amalfi (North-eastern Antioquia Region)

Medellin (Metropolitan Area of the Aburra Valley)

\section{Raw earth construction techniques}

As the main component of the investigation, metal structure bahareque and CEB housing prototypes were fully developed in one of the Municipalities visited during the course of the investigation. Both of the methods were used to build two different houses in Marinilla, Antioquia. The following is an outline of the methods used during the course of the research project to produce both metal structure bahareque and CEBs.

\subsection{Metal structure bahareque (wattle and daub)}

Traditional bahareque (wattle and daub) consists of a wooden, or bamboo structure, stuffed with a mixture of soil and hay. In many cases it is covered with a layer of stucco on both interior and exterior walls.

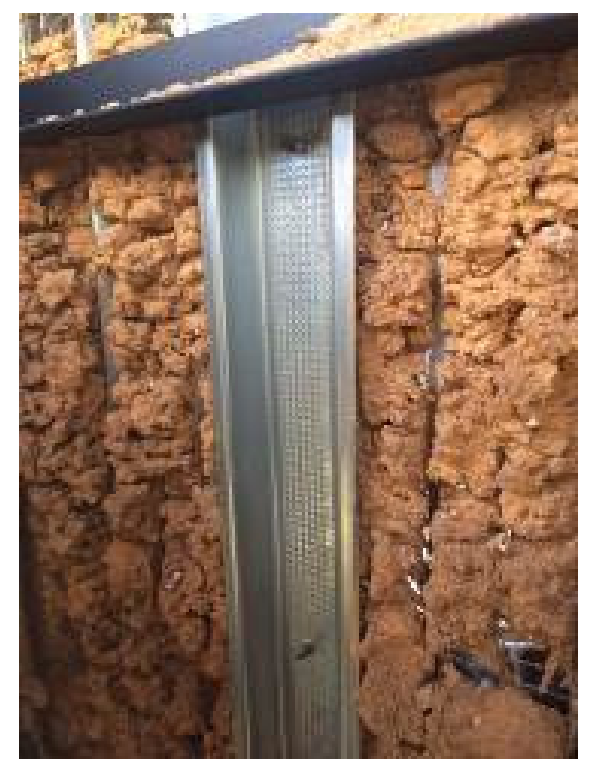

Figure 3: Metal structure bahareque construction process. 
The method used for the research project replaces the wooden or guadua structure of traditional bahareque with steel and replaces the wattle with wire mesh whenever it is needed. The prototype house was built in Marinilla using this same procedure.

Metal structure bahareque was designed with a more urban application in mind than CEB houses. The system allows for the metal structure to be produced serially and on a large scale and then grouped and transported to a construction site where the structure is assembled before applying the raw earth and finishing touches.

A metal structure, built from steel profiles, is used to build the structural support for the wall, after which a surface is built out of either wire mesh or wooden structure. Clay-rich soil mixed with hay is applied and pressed onto the structure allowing it to set in place. As with traditional bahareque different layers of stucco can be added to both the interior and exterior faces of the wall. The use of metallic profiles allows the metal structure bahareque to comply with Colombian construction regulations and because it allows the building process to be carried out on an individual or industrial scale. The use of steel profiles in the structure also allows for the construction materials to be transported easily in parts and assembled on site.

\subsection{Compressed earth blocks}

The second method explored in the research project involves the use of a machine commercially available in Colombia, which is similar conceptually and in operation to the CINVA RAM developed by the National University of Colombia in the 1950s.

The CEBs are made from selected earth, moulded, machine pressed and unmoulded immediately. To improve the physical and mechanical properties of the CEBs (such as compression resistance, resistance to wind erosion, waterproofing and durability) granulometric stabilisation can be used. To do this different proportions of soil and a stabiliser, generally lime or cement are used. It is possible to manufacture stabilised CEBs in different shapes and sizes, the most common of which are completely solid, or with vertical or horizontal perforations.

\subsubsection{Steps for the manufacture of CEBs}

2.2.1.1 Preparation of soil Soil - preferably dry soil - is selected, pulverized and passed through a sieve. Mechanical pulverisation and a sieve made out of $5 \mathrm{~mm}$-hole wire mesh are recommended for this process.

2.2.1.2 Preparation of soil-cement mixture Once the earth has been pulverized and sieved it is then mixed in varying proportions with cement. The proportion is previously determined from the characteristics of the soil used for the process. Cement-soil mixtures are tested for compression resistance according to Colombian construction regulations. The minimum quantity of cement needed for the cement-soil mixture to pass the compression test is used to prepare the 
CEBs. The mixture is prepared dry and then water is slowly added until the mixture has reached the appropriate humidity for pressing.

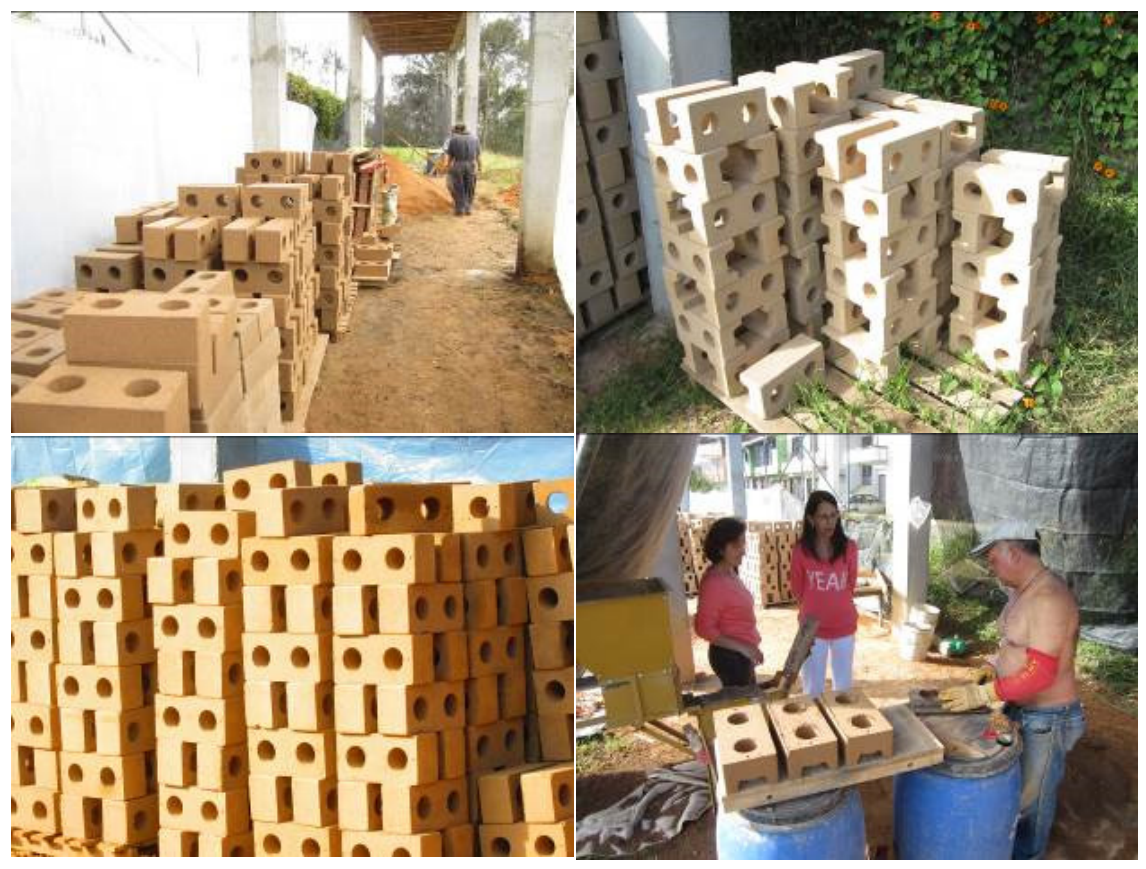

Figure 4: Compressed earth blocks (CEBs).

2.2.1.3 Production of CEBs The cement-soil mixture is placed in the pressing machine, where it is pressed and removed from the mould. It is then moved onto a flat, smooth surface, away from sunlight, wind and rain. 6 hours after the pressing and for the following 7 days the CEBs must be kept humid by means of scheduled watering. This last step ensures proper hydration of the cement and achieves a greater material strength for the CEBs. This step is also referred to as the curing of the CEBs. Once cured, the CEBs can be stored in piles of up to $1.5 \mathrm{~m}$ tall and should be covered to retain humidity and prevent deterioration.

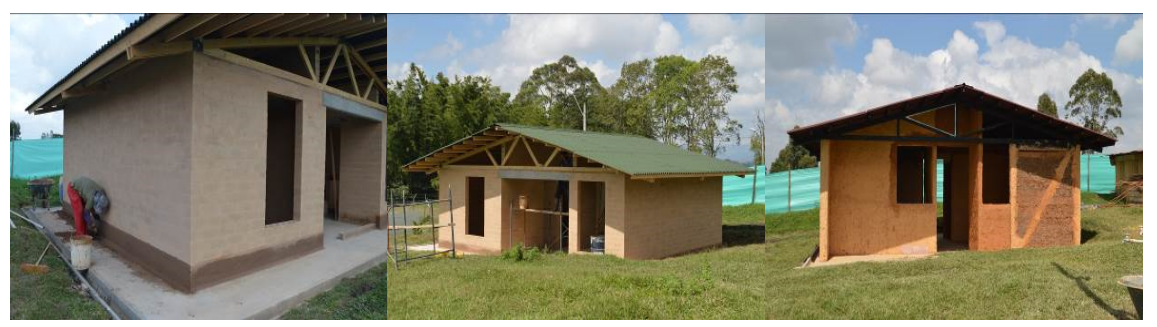

Figure 5: $\quad$ EBB and bahareque prototypes. 


\section{Raw earth house prototypes}

After selection and development of both the CEB and metal structure bahareque the next step in the research process was to construct different housing prototypes based on these construction elements. The prototypes were built in Marinilla, Antioquia, in the Oriente Antioqueño region (Eastern Antioquia) the site of one of the workshops and visits carried out in the earlier steps of the research project. Both prototypes were built using soil obtained near the construction site, selected and tested to meet the technical construction requirements of Colombian construction regulations.

\subsection{Design and construction of the metal structure bahareque prototype}

The design is initially intended as a one floor urban housing solution. The prototype is meant to satisfy the housing needs of a single 4-5-member family, predominantly for urban settings. The relatively thin walls built using the steel profiles maximize available area without affecting the structural capacity of the buildings. This is especially important considering the amount of terrain available for low-income housing developments. The houses are also developed in groups of three, where the houses share walls to further reduce their footprint.

Because metal structure bahareque is predominantly meant for urban development, houses are generally two-story houses.
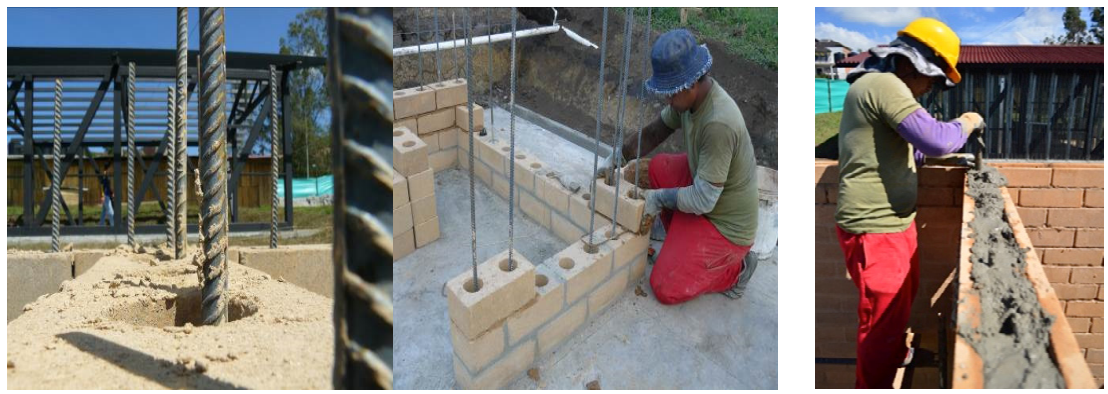

Figure 6: Hollow core CEB and metal reinforcement.

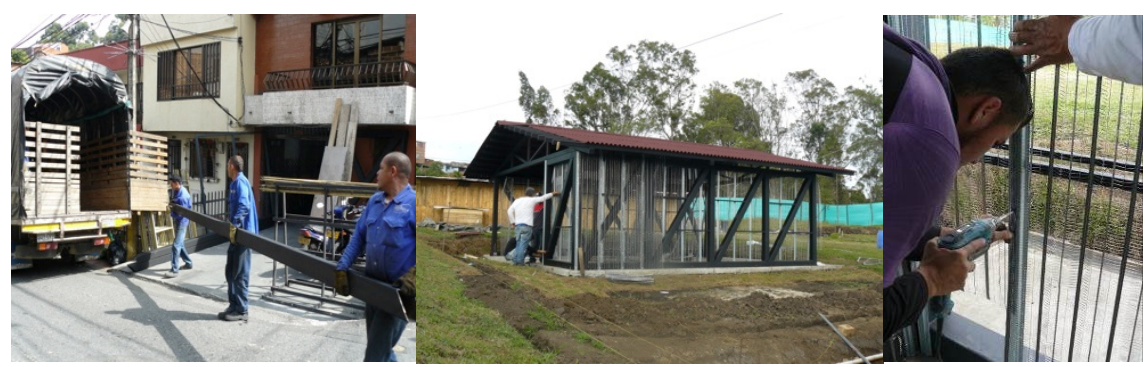

Figure 7: Metal structure bahareque. 
The metal structure bahareque houses were designed with a more urban development scenario in mind. However, their potential for rural housing was also recognized during the investigation. In rural areas, especially those that are difficult to access, the houses can be built from scratch with all assembly of the metal structure done on site. Metal profiles can be easily transported unassembled to areas where prefabricated panels would be impossible to transport. The walls are finished using resources available near the building site. Where wood is available, it can be used to build the structure for the earth mixture to be applied on. Where it is not available, or where quality and uniformity considerations are important, wire mesh can be used as well. The soil used in the walls is also obtained from the building site, or as near as possible to avoid increasing transport costs. The houses can also be built to stand alone, which is more convenient in rural areas than the three-house groups used for urban settings.

\subsection{Design and construction of CEB house prototype}

This house is initially designed to satisfy the technical requirements for rural housing. Rural communities are involved in the manufacture of the CEBs and the construction to promote the appropriation of the techniques. CEBs are made with a hollow core to allow easier transport. Perforated CEBs allow for the use of steel rods and mortar for higher structural capacity. The same cement-soil mixture used to manufacture the CEBs can be used to bind the blocks to each other during the construction.

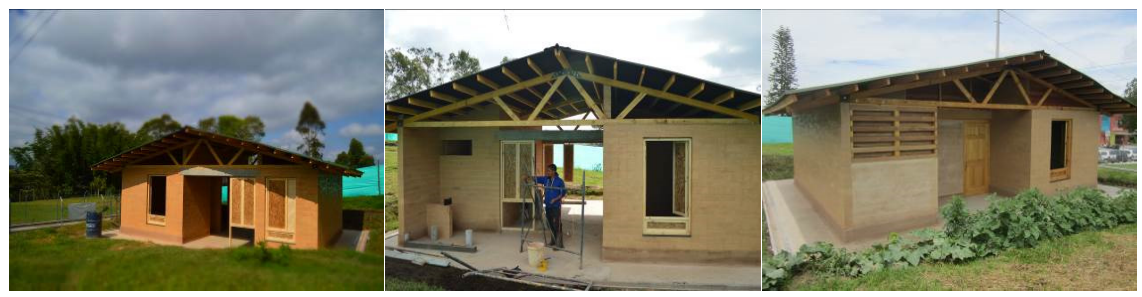

Figure 8: Construction of CEB.

Both of the housing designs - using the CEB and metal structure bahareque as techniques - are built using wooden trusses for roofing. This roofing can be left open or closed depending on the need to dissipate or contain heat inside the buildings. If needed the trusses are closed using bahareque, even in the CEB houses, this is generally done in the colder regions, whereas in the warmer regions of Antioquia the trusses are left open to ventilation and cooler indoor spaces.

\section{Conclusions}

In architecture, sustainability is considered the rational use of local materials. When raw earth is used as a construction material the generation of toxic gases is reduced, the generation of solid residue is reduced, the consumption of water for production is reduced. Earth as a material conserves heat, preserves wood and 
other materials from deterioration, does not need industrial transformations with high energy costs, it can be completely reused and recycled, saves energy, reduces environmental contamination, possesses excellent thermal characteristics, it regulates both heat and humidity inside the houses through thermal inertia. All over the world, raw earth can be used easily by people without the need for previous experience or advanced technical knowledge. The use of raw earth as a construction material favours sustainability and the biological equilibrium, integrating the energy cycles of the ground and air, allowing to design easy-toconstruct sustainable projects of simple application in the context of Antioquia, and as a result in the Colombian context.

\section{References}

[1] Rotondaro, R. Influencia de la innovación tecnológica en las tradiciones constructivas y proyectuales: el caso de la Arquitectura de Tierra contemporánea del NOA, Seminario de Crítica, Vol. 180, pp. 1-35, 2012.

[2] National Construction Code (NTC 5324-2004). Edited by the Colombian Institution of technical regulations and certifications (ICONTEC), Bogota, 2004-12-01.

[3] National Seismic-resistance Code (NSR-2010). Bogota, Colombia, March 2010.

[4] Saldarriaga Roa, A. Guía hábitat rural y vivienda campesina en Colombia, Premio Corona Pro Hábitat, 2012. 